\title{
Estágio supervisionado II: relato de experiência em turmas do segundo ano do ensino médio da escola pública Dom Pedro II em Belém - Pará, Amazônia, Brasil
}

\author{
Supervised internship II: experience report in classes of the second year of high school Dom Pedro \\ II public school in Belém-Pará, Amazon, Brazil \\ Pasantía supervisada II: informe de experiencia en clases del segundo año de secundaria de la \\ escuela pública Dom Pedro II en Belém- Pará, Amazonía, Brasil
}

Recebido: 07/01/2022 | Revisado: 12/01/2022 | Aceito: 14/01/2022 | Publicado: 16/01/2022

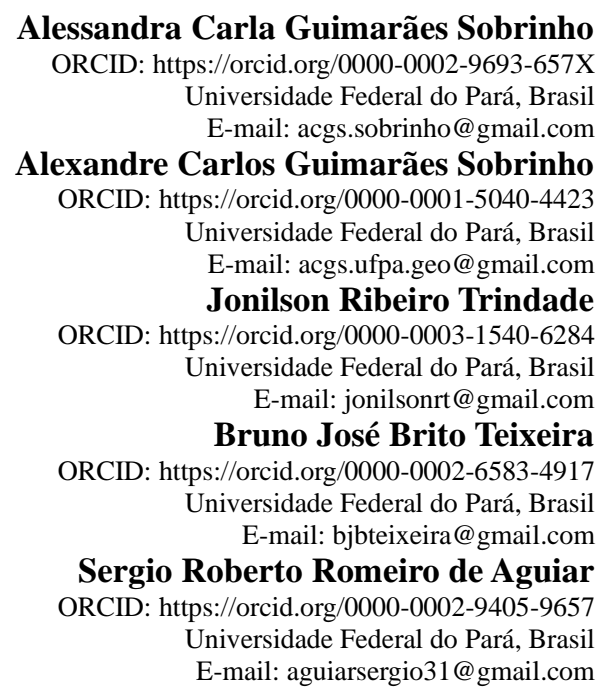

\begin{abstract}
Resumo
O presente artigo partiu da experiência do Estágio Supervisionado II, sendo atividade obrigatória do curso de educação à distância $(\mathrm{EaD})$ de Licenciatura em Química, da Universidade de Uberaba (UNIUBE) polo Belém-Pará. A escrita deriva de um exercício prático e reflexivo do estágio supervisionado nas turmas do segundo ano do ensino médio da Escola Estadual de Ensino Fundamental e Médio Dom Pedro II, localizada na Amazônia brasileira, na cidade de Belém no Estado do Pará. A prática do estágio foi realizada em turmas do ensino médio, sendo feitas as observações das aulas, a colaboração mediante a monitoria e docência em sala de aula, sendo todas as atividades devidamente acompanhadas pelo supervisor de estágio. O estágio conferiu uma carga horaria total de 240 horas e teve como objetivo analisar a vivência do estágio, mais precisamente, a observação do bairro onde se localiza a escola, a escola e sua história, conhecimento dos espaços, materiais e recursos pedagógicos, fazer as reflexões e análises sobre o projeto político pedagógico (PPP), além de, observações e análises do ensino de química e pôr fim, a monitoria e docência para as turmas do ensino médio. $O$ estágio supervisionado possibilitou a união entre a teoria e a prática em sala de aula, auxiliando na construção da identidade docente com compromisso, disciplina e planejamento para ações mais efetivas.
\end{abstract}

Palavras-chave: Educação; Amazônia; Vivência; Ensino Médio; Formação docente.

\begin{abstract}
This article started from the experience of Supervised Internship II, being a mandatory activity of the distance education course (DEC) of chemistry degree, university of Uberaba (UNIUBE) pole Belém-Pará. The writing derives from a practical and reflective exercise of supervised internship in the second year of high school classes of the Escola Estadual de Ensino Fundamental e Médio Dom Pedro II, located in the Brazilian Amazon, in the city of Belém in the State of Pará. The practice of the internship was performed in high school classes, being made the observations of the classes, collaboration through monitoring and teaching in the classroom, being all activities duly accompanied by the internship supervisor. The internship conferred a total hourly load of 240 hours and aimed to analyze the experience of the internship, more precisely, the observation of the neighborhood where the school is located, the observation of the school and its history, knowing the spaces, materials and pedagogical resources, making reflections and analyses on the political pedagogical project (PPP), in addition to observations and analyses of chemistry teaching and put an
\end{abstract}


end to monitoring and teaching for high school classes. The supervised internship enabled the union between theory and practice in the classroom, assisting in the construction of the teacher identity with commitment, discipline and planning for more effective actions.

Keywords: Education; Amazon; Experience; Middle school; Teacher training.

\section{Resumen}

Este artículo parte de la experiencia de la Pasantía Supervisada II, siendo una actividad obligatoria del curso de educación a distancia (EaD) de un Grado en Química, de la Universidad de Uberaba (UNIUBE) polo Belém-Pará. La escritura deriva de un ejercicio práctico y reflexivo de pasantía supervisada en el segundo año de las clases de secundaria de la Escola Estadual de Ensino Fundamental e Médio Dom Pedro II, ubicado en la Amazonía brasileña, en la ciudad de Belém en el Estado de Pará. La práctica de las prácticas se realizó en las clases de secundaria, realizándoles las observaciones de las clases, la colaboración a través del seguimiento y la docencia en el aula, siendo todas las actividades debidamente acompañadas por el supervisor de prácticas. La pasantía confirió una carga total por hora de 240 horas y tuvo como objetivo analizar la experiencia de la pasantía, más precisamente, la observación del barrio donde se encuentra la escuela, la escuela y su historia, conociendo los espacios, materiales y recursos pedagógicos, haciendo reflexiones y análisis sobre el proyecto político pedagógico (PPP), además de observaciones y análisis de la enseñanza de la química y poner fin al monitoreo y la enseñanza para las clases de secundaria. La pasantía supervisada permitió la unión entre la teoría y la práctica en el aula, ayudando en la construcción de la identidad docente con compromiso, disciplina y planificación para acciones más efectivas.

Palabras clave: Educación; Amazona; Experiencia; Secundaria; Formación del profesorado.

\section{Introdução}

O estágio supervisionado apresenta-se como uma instância pedagógica para assegurar a formação teórico-prática dos alunos, funcionando ao mesmo tempo, como promotor da interação entre a universidade e a comunidade em âmbito local e regional. Pretende-se construir uma experiência de estágio que propicie a formação de um profissional autônomo que reflete, toma decisões e cria durante sua ação pedagógica, contemplando o perfil do profissional que se pretende formar: um professoreducador comprometido com o desenvolvimento humano em todas as suas dimensões (UNIUBE, 2021).

O estágio é o primeiro com o ambiente escolar, aplicando todo o conteúdo teórico prática, aproximando o aluno do contexto no qual ele atuará enquanto profissional (Pimenta \& Lima, 2012). Segundo a Lei 11.788, de 25 de setembro de 2008, no Artigo 1": "Estágio é ato educativo escolar supervisionado, desenvolvido no ambiente de trabalho, que visa à preparação para o trabalho produtivo de educandos que estejam frequentando o ensino regular em instituições de educação superior, de educação profissional, de ensino médio, da educação especial e dos anos finais do ensino fundamental, na modalidade profissional da educação de jovens e adultos" (Brasil, 2008, Art. $1^{\circ}$ ).

O estágio supervisionado II é um dos componentes obrigatórios do curso de educação à distância (EaD) de Licenciatura em Química, da Universidade de Uberaba (UNIUBE), sendo um componente de suma importância no processo de formação docente, independentemente de ser obrigatório, o estágio é uma chance de aprofundar conhecimentos e habilidades em área de interesse do aluno, oportunizando situações problemáticas nas organizações, sendo possível proposições, avaliações, bem como testar modelos e instrumentos para a construção do conhecimento por parte do aluno (Roesch, 1996).

Diante do exposto, o artigo teve como objetivo relatar a experiência durante o estágio supervisionado II em turmas do segundo ano do ensino médio da Escola Estadual de Ensino Fundamental e Médio Dom Pedro II em Belém do Pará, conhecendo a realidade da sala de aula, participando das atividades próprias da profissão docente e vivenciando as metodologias próprias à construção do conhecimento sobre as práticas pedagógicas docentes.

\section{Metodologia}

O presente artigo, Estágio supervisionado II: relato de experiência em turmas do segundo ano do ensino médio da escola pública Dom Pedro II em Belém - Pará, Amazônia, Brasil, teve como objetivo fazer um estudo de caso, descrevendo a 
experiência durante o estágio supervisionado e a importância do estágio para a formação docente durante o curso EaD de Licenciatura em Química.

O estágio foi realizado na região Amazônica, na cidade de Belém no Estado do Pará na Escola Estadual de Ensino Fundamental e Médio Dom Pedro II. Durante o estágio supervisionado foi observado o bairro onde se localiza a escola, escola e sua história, conhecimento dos espaços, materiais e recursos pedagógicos, reflexões e análises sobre o projeto político pedagógico, observações e análises do ensino de química, monitoria e docência para as turmas do ensino médio. O estágio conferiu uma carga horaria total de 240 horas, sendo distribuídas de acordo com a Tabela 1 abaixo:

Tabela 1 - Distribuição de carga horária para o Estágio Supervisionado II.

\begin{tabular}{lccc}
\hline \multicolumn{1}{c}{ Atividades } & \multicolumn{2}{c}{ Carga Horária } \\
\cline { 2 - 4 } & Orientação & Estudo & Campo \\
\hline 1- Orientações gerais sobre o estágio & 10 & - & - \\
2- A escola no ensino médio & - & 80 & 30 \\
3- A docência no ensino médio & - & 40 & 60 \\
4- Elaboração do relatório pedagógico & - & 20 & - \\
\hline Total & 10 & 140 & 90 \\
\hline
\end{tabular}

Fonte: Autores.

\section{Resultados e Discussão}

\subsection{Observações do bairro onde se localiza a Escola Estadual de Ensino Fundamental e Médio Dom Pedro II}

Toda escola está situada em uma comunidade dentro de um contexto social "sobre o qual não tem controle, mas que influencia fortemente as relações estabelecidas nos espaços escolares e, consequentemente, o processo de ensino/aprendizado." (Soares, 2004, p.86). O local onde a escola está situada define, as suas relações com o meio, com as pessoas no contexto da aprendizagem que de acordo com Garcia (2017):

"Dependendo de sua localização, urbana ou zona rural, central ou periférica, ou em áreas de risco, como nas favelas, os símbolos e os signos do entorno incorporados na linguagem e compartilhados pelas pessoas afetam e influenciam as aprendizagens, as experiências realizadas, o currículo desenvolvido na escola, entre outros. Os saberes prévios, como já conhecido, interferem na construção do conhecimento".

Escola Estadual de Ensino Fundamental e Médio Dom Pedro II com a Entidade Mantenedora a Secretaria Executiva de Educação - SEDUC está localizada na Travessa Lomas Valentinas, 2140, bairro do Marco na cidade de Belém (Figura 1).

Figura 1 - Localização da Escola Estadual de Ensino Fundamental de Médio Dom Pedro II em Belém -Pará.

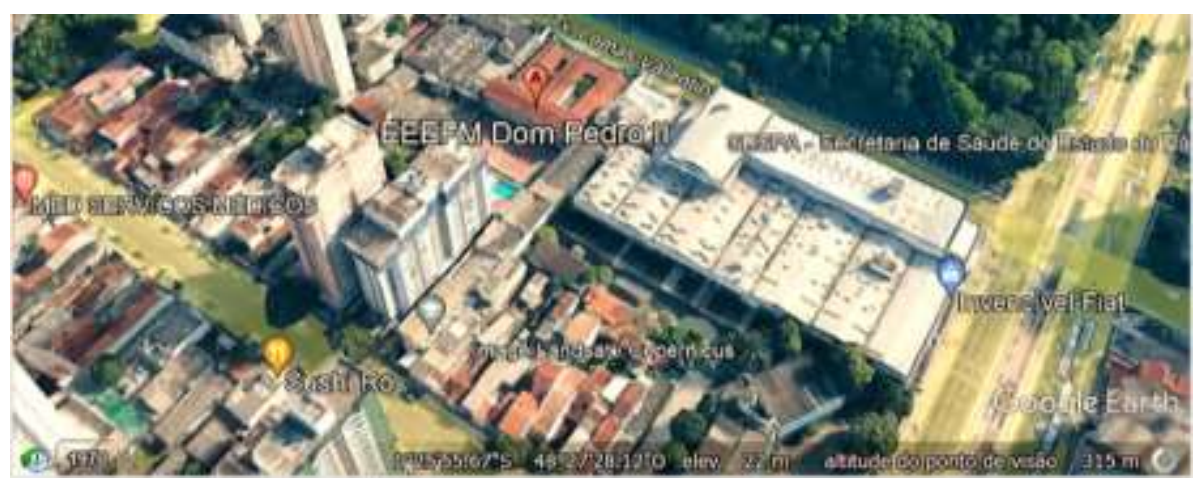

Fonte: Google Earth (2022). 
O bairro do Marco situa-se no município de Belém, e é assim chamado por ter sido colocado um "Marco" na Avenida Almirante Barroso, na confluência com a avenida Dr. Freitas - conhecida também por "Bandeira Branca", para sinalizar a primeira légua patrimonial de extensão da cidade de Belém, contando a partir do Forte do Castelo (Silva, 2016). As áreas vizinhas à Escola caracterizam-se por um contexto urbanizado, compostos por casa e prédios residenciais e comerciais situados em avenidas, ruas, passagens, becos e vielas. A sua frente fica o Bosque Rodrigues Alves - Jardim Botânico da Amazônia.

Observou-se que o bairro apresenta, grandes empresas no ramo do varejo e comércios de pequeno e médio porte, padarias e bares, situadas à Avenida Almirante Barroso. Existem também farmácias, clínicas médicas e hospitalares, um complexo de atendimento à saúde pertencente à Prefeitura Municipal de Belém - IPAMB (Instituto de Previdência e Assistência Municipal de Belém), A EMBRAPA (Empresa Brasileira de Pesquisa Agropecuária), o INCRA (Instituto Nacional de colonização e Reforma Agrária), além de Igrejas ou Templos Católicos, Adventistas, Batista, Assembleia de Deus, Igreja Messiânica e Searas de Umbandas, apresentado uma grande parte de área urbana bem saneada, notadamente nas áreas mais movimentadas, sendo atendido por várias linhas de transporte coletivo tais como: Tamoios, Ceasa, Cidade Nova VI - UFPA, Terra Firme, Pedreira Nazaré, Pedreira Lomas e Icoaraci - UFPA. Além de espaço de Arte, Cultura e Lazer do SESI, Restaurantes, a RBA (Rede Brasil Amazônia de Televisão), o Jardim Botânico Bosque Rodrigues Alves, posto de gasolina, a feira da "Bandeira Branca", o Seminário Teológico e uma rede de escolas - federais, estaduais, municipais e particulares.

O entorno escolar pode ampliar a qualidade da aprendizagem dos alunos e dos professores, além de possibilitar parcerias produtivas, dinamizando as práticas educativas de forma significativa. No entanto, precisa ser conhecido e explorado adequadamente pelos atores escolares, podendo contribuir para a melhoria da escola (Garcia, 2017).

\subsection{A escola e sua história}

A escola foi inaugurada em 02/12/1925, com a denominação de Grupo Escolar "D. Pedro II", na gestão do então Governador do Estado Exm ${ }^{\circ}$ Sr. Dyonisio Bentes, tendo como primeira Diretora a professora Plácida Alves Cardoso. A diretora atual, eleita pela comunidade escolar, é a professora Sandra Rejane Sousa, que tem como Vice-diretora a professora Maria das Graças de A. Lima.

\subsection{Conhecimento dos espaços, materiais e recursos pedagógicos}

A escola funciona com um total de 520 alunos distribuídos nos três turnos, conta com corpo docente constituído de 56 professores todos com Licenciatura Plena e 48 funcionários. A escola apresenta as seguintes dependências: sala da direção, sala de vice direção, secretaria, sala dos professores, treze salas de aula, quadra poliesportiva, sala de leitura, sala de informática educativa, copa/ cozinha, área de alimentação, sala de reprografia, quatro banheiros e área livre. Na Figura 2 apresenta-se alguns ambientes da escola citados anteriormente.

Figura 2 - Diferentes ambientes da Escola Estadual de Ensino Fundamental e Médio Dom Pedro II, área externa (A), banheiros (B), área de alimentação (C), quadra poliesportiva (D), sala de leitura (E) e sala de informática (F).

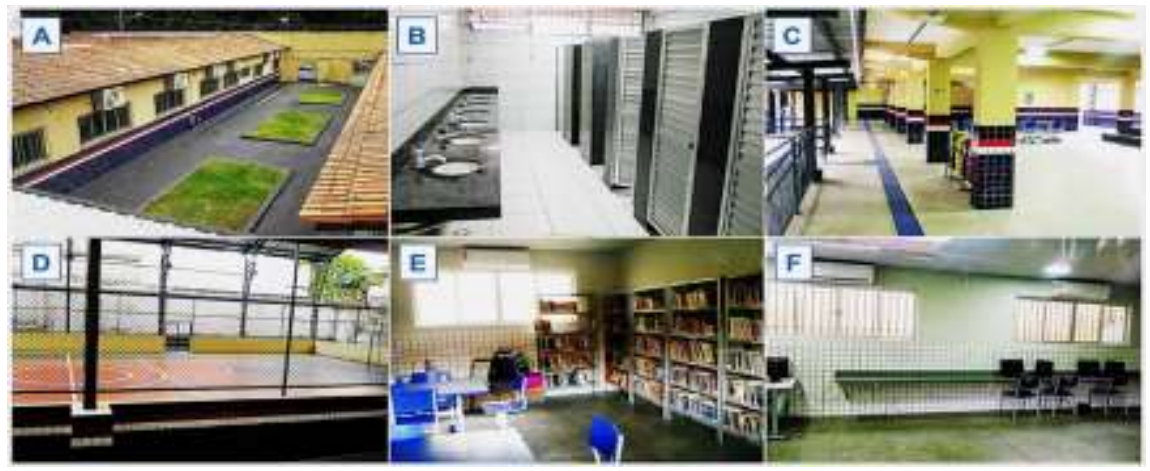

Fonte: Autores. 
Os espaços são diferenciados permitindo o aprendizado em diferentes ambientes e de acordo com Frago \& Escolano (1998, p. 27, 45):

Os espaços educativos, como lugares que abrigam a liturgia acadêmica, estão dotados de significados e transmite uma importante quantidade de estímulos, conteúdos e valores do chamado currículo oculto... [...] a arquitetura escolar pode ser vista como um programa educador, ou seja, como um elemento do currículo invisível ou silencioso, ainda que ela seja, por si mesma, bem explícita ou manifesta. [...].

A escola Estadual e Ensino Fundamental e Médio Dom Pedro II, atende nas modalidades de Ensino Fundamental, Médio Regular, Atendimento Educacional Especializado (AEE) e Educação de Jovens e Adultos (EJA) - ensino fundamental e médio.

A escola foi recém reformada, assim, os ambientes amplos, modernos, equipados, limpos e organizados. Todas as salas de aula apresentam quadro branco, ventilador, ar-condicionado e mobiliadas com carteiras novas (Figura 3).

Figura 3 - As salas de aula, externamente (A) e internamente com cadeiras, mesa, armário, quadro branco, ventilador e arcondicionado (B).

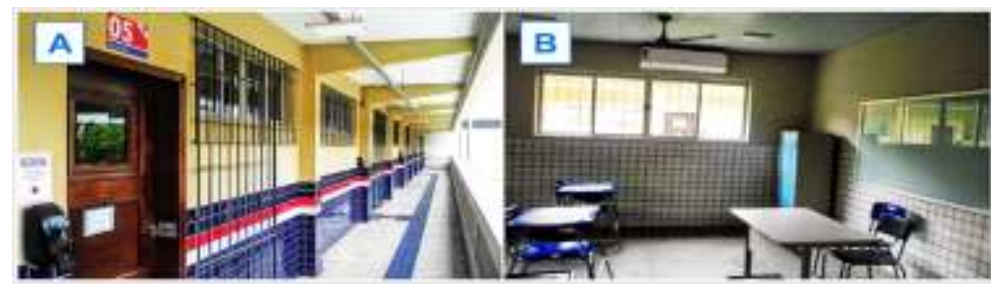

Fonte: Autores.

Os espaços, materiais e recursos pedagógicos da Escola Estadual de Ensino Fundamental e Médio Dom Pedro II, são adequados para a clientela diversificada, que em sua maioria são alunos proveniente de bairros e municípios distantes (Bengui, Ananindeua, Águas Lindas, Tenoné, Cidade Nova, Outeiro, Benevides e Mosqueiro), com situação socioeconômica de baixa renda. Outros moram no próprio bairro, porém a situação não é diferenciada, também há alunos que trabalham para ajudar na renda familiar.

A estrutura física da escola, assim como sua organização, manutenção e segurança, revelam muito sobre a vida que ali se desenvolve ou que se quer desenvolver (Cedac 2013, pág. 10). O ambiente físico da escola e da sala de aula devem ser adequados, com acesso aos recursos didáticos e com condições apropriadas para o desenvolvimento do trabalho do professor, tais como: remuneração, carga horária de trabalho flexível, número adequado de alunos por turma e a formação continuada dos professores (Carmo, 2012; Mota et al., 2021).

\subsection{Reflexões e análises sobre o projeto político-pedagógico (PPP)}

Conforme definido na Lei de Diretrizes e Bases da Educação Nacional (LDB, Lei no 9.394/1996), a Base Nacional Comum Curricular - BNCC (Brasil, 2008) deve nortear os currículos dos sistemas e redes de ensino das Unidades Federativas, como também as propostas pedagógicas de todas as escolas públicas e privadas de Educação Infantil, Ensino Fundamental e Ensino Médio, em todo o Brasil (Brasil,1996).

A elaboração do projeto político pedagógico (PPP) deve propiciar uma reflexão crítica sobre a sociedade, as relações entre os atores envolvidos, a realidade escolar e as ações desenvolvidas pela instituição educativa, sendo de fundamental importância a participação de profissionais, alunos, pais e comunidade (Guedes et al., 2017). De acordo com os autores Garcia \& Queiroz (2009, p. 119): [...] ao construir o seu projeto, os sujeitos não só definem as regras que regem o coletivo e a sua 
identidade, como também reconstroem suas relações e práticas escolares, o que lhes confere consciência das possibilidades e da capacidade do grupo de levar adiante um projeto coletivo de educação.

O Projeto Político Pedagógico (PPP) da Escola Estadual de Ensino Fundamental e Médio Dom Pedro II, foi construído coletivamente e se baseia nas diretrizes emanadas pela SEDUC, fundamentadas no Materialismo-HistóricoDialético, levando em consideração a realidade histórico-social-econômica onde a escola e alunos estão inseridos. O PPP da escola propõe-se a estabelecer procedimentos, critérios e metas norteadora para as ações pedagógicas através dos agentes multiplicadores do ensino, fundamentando-se na educação construtivista, sendo centrada no tripé: interdisciplinaridade, competência e habilidade transformando-a em escola inclusiva, entendendo que a escola deve ser um espaço de formação dos sujeitos e precisa estar preparada para oferecer aos alunos uma formação que lhe permita transitar nesse mundo de forma crítica como sujeitos interventores no futuro, capazes de construir o hoje.

Nesta perspectiva, de acordo com o PPP a escola tem como principal missão que todos os segmentos da escola construam, juntos, estratégias que possibilitem a "Reconstrução" da Escola como instrumento de valorização do SER social, visando sempre o exercício da cidadania, partindo de princípios de democratização, integração e solidariedade, na busca de uma sociedade igualitária e cooperativa preparando os alunos para o trabalho e exercício consciente da cidadania, com propostas resolvidas através de discussões, reuniões, encontros, seminários, palestras, oficinas para a comunidade educativa para a construção de um trabalho integrado visando à melhoria da qualidade de ensino e vida, assim como, as relações entre escola - comunidade - família, considerando-se a realidade histórica social da comunidade, pois de acordo com o PPP da escola o processo educativo é coletivo e articulado a outros espaços, atuando em um contexto social amplo de forma que todos devem participar e serem alcançados, e essa reflexão não se encerra em determinados momentos da vida ou da carreira, mas é permanente e contínua. A participação dos pais e da comunidade na escola é representativa, demonstrada por meio do Conselho Escolar, Associação de Pais, Mestres e Funcionários e nas atividades desenvolvidas pela escola.

\subsection{Observação e análise do ensino de química nas turmas do segundo ano do ensino médio}

Ao me dirigir para a sala de aula, nas turmas do segundo ano do ensino médio, fui apresentada aos alunos pelo professor e supervisor de estágio, Sergio Roberto Romeiro de Aguiar. Durante o desenvolvimento do estágio pude primeiramente observar o desenvolvimento do professor em sala, pois de acordo com o autor Pereira (2018), a observação do cotidiano escolar, ajudará o aluno estagiário a desenvolver seu trabalho da melhor forma possível, pois através da observação do cotidiano da referida escola o aluno tentará inserir as atividades planejadas de cordo com o contexto vivenciado pela comunidade escolar.

As aulas do professor Sergio Aguiar, foram em sua maioria expositiva dialogada abordando assuntos referentes a disciplina de química no ensino médio, com a utilização de apostilas, quadro branco e pinceis. Apesar do número reduzido de alunos, eles foram participativos em sala de aula o que tornou as aulas dinâmicas, sendo possível observar as generalizações da aprendizagem, ou seja, o aluno conseguia transpor um conhecimento aprendido em um contexto para uma outra situação semelhante. A relação professor-aluno é democrática de forma que todos são atores no processo educacional, e ativos no processo de ensino-aprendizagem, o professor usa o seu poder de forma equilibrada, trazendo uma visão de conhecimento associada ao cotidiano, fazendo da interação ensinante-aprendente significativa tanto em termos cognitivos quanto afetivo. Além disso, as avaliações feitas pelo professor foram ferramentas para o aperfeiçoamento do processo de aprendizagem, para a estabilidade do que foi aprendido, que é uma característica da aprendizagem efetiva, enriquecendo o que foi aprendido a partir da criação de uma teia de conhecimentos e conceitos.

O exercício de qualquer profissão é prático e a profissão docente não é diferente, assim o estágio, não deve se reduzir a observação do professor em sala de aula e também não deve se reduzir a algumas horas no cumprimento de obrigações, mas 
deve-se entender o estágio em uma perspectiva mais ampla, que possibilite a compreensão dentro do ensino, com definições assertivas que proporcionam um aprender a aprender e um saber pensar, raciocinar, investigar, tendo como foco o desenvolvimento de habilidades e competências.

\subsection{Monitoria e docência nas turmas do segundo ano do ensino médio}

De acordo com a Lei n. 11.788, “estágio é ato educativo escolar supervisionado, desenvolvido no ambiente de trabalho, que visa à preparação para o trabalho produtivo de educandos [...]” (Brasil, 2008, art. $1^{\circ}$ ), além disso, a Lei de Diretrizes e Bases da Educação Nacional - LDB, a Lei № 9.394/96 estabelece a importância das atividades através da monitoria no processo de formação dos estudantes do ensino superior (Brasil, 1996).

A monitoria durante a graduação está inserida como uma atividade de apoio aos processos de ensino e de aprendizagem, bem como, a possibilidade de aquisição de conhecimento, bem como promover a preparação para a formação docente (Haag et al., 2008; Nascimento et al., 2011; Eskenazi et al., 2013; Souza \& Gomide, 2013; Frison, 2016) A monitoria contribui para o desenvolvimento da competência da docência, possibilitando uma postura reflexiva e crítica da prática educacional (Reis et al., 2008; Nascimento et al., 2011; Souza \& Gomide, 2013; Sousa \& Fernandes, 2016; Cruz, 2017).

Durante a monitoria pude entender que é necessário e ético ensinar com o comprometimento em formar cidadãos, pois a profissão docente deve atuar em prol da sociedade, entendendo que a mediação no processo ensino-aprendizagem, construirá pontes para o conhecimento, auxiliando na formação de uma sociedade crítica e pensante, através de práticas pedagógicas eficientes, que reflitam a autonomia pedagógica do professor e as competências, além de ser democrática e cidadã.

\subsubsection{Plano (s) de aula (s) para a docência no Ensino Médio}

A docência durante o estágio supervisionado, consistiu primeiramente na elaboração do plano de aula (Plano A, Plano $\mathrm{B}$, Plano C):

\subsubsection{Plano de aula $A$}

○ Nome da escola: Escola Estadual de Ensino Fundamental e Médio Dom Pedro II,

○ Nome da Estagiária: Alessandra Carla Guimarães Sobrinho

○ Tema da aula: Aula experimental, construção de equipamento alternativo para a filtração de água.

○ Público-alvo: $2^{\circ}$ ano do Ensino Médio

○ Carga horária: 90 min (2H/AULA).

○ Procedimentos Metodológicos:

$\checkmark$ Os materiais necessários para o desenvolvimento do procedimento são: garrafa pet de 2 litros; tesoura; régua; algodão; carvão em pó, areia; pedras pequenas, água com impurezas;

$\checkmark$ Com os materiais em mãos os alunos devem cortar a garrafa pet em dois pedaços (parte com o gargalo e parte da base). Após o corte, o aluno utilizará a parte que contém o gargalo para acomodar todos os itens nessa ordem: algodão, carvão, areia, pedras, formando assim o filtro, esse sistema se encaixará com a parte da base da garrafa Pet que servirá de suporte para o filtro;

$\checkmark$ Com o filtro alternativo montado, o aluno deverá inserir a água com impurezas e observar a filtração da água;

$\checkmark$ O carvão mineral é o componente purificador da água, a areia é responsável pela retenção das partículas sólidas suspensas e as pedras e algodão servem de suporte/filtração. Ao final da aula, será proposto um debate a respeito da poluição da água e a importância da sua preservação. 


\subsubsection{Plano de aula $B$}

- Nome da escola: Escola Estadual de Ensino Fundamental e Médio Dom Pedro II

○ Nome da Estagiária: Alessandra Carla Guimarães Sobrinho

○ Tema da aula: Características do átomo e distribuição eletrônica.

○ Público-alvo: $2^{\circ}$ ano do Ensino Médio

○ Carga horária: 90 min (2H/AULA).

\section{○ Procedimentos Metodológicos:}

$\checkmark$ A aula foi teórica expositiva, interativa e dialogada, contendo: levantamento dos conhecimentos prévios dos alunos. Inicialmente foi apresentado o tema do dia e o tópico a ser abordados em sala de aula. Foram utilizados os seguintes recursos didáticos: apostila (Figura 4), quadro e pincel. Ao final da aula foi proposto exercícios de fixação para avaliar a aprendizagem dos alunos em relação a temática.

Figura 4 - Apostila elaborada para a aula de características do átomo e distribuição eletrônica.

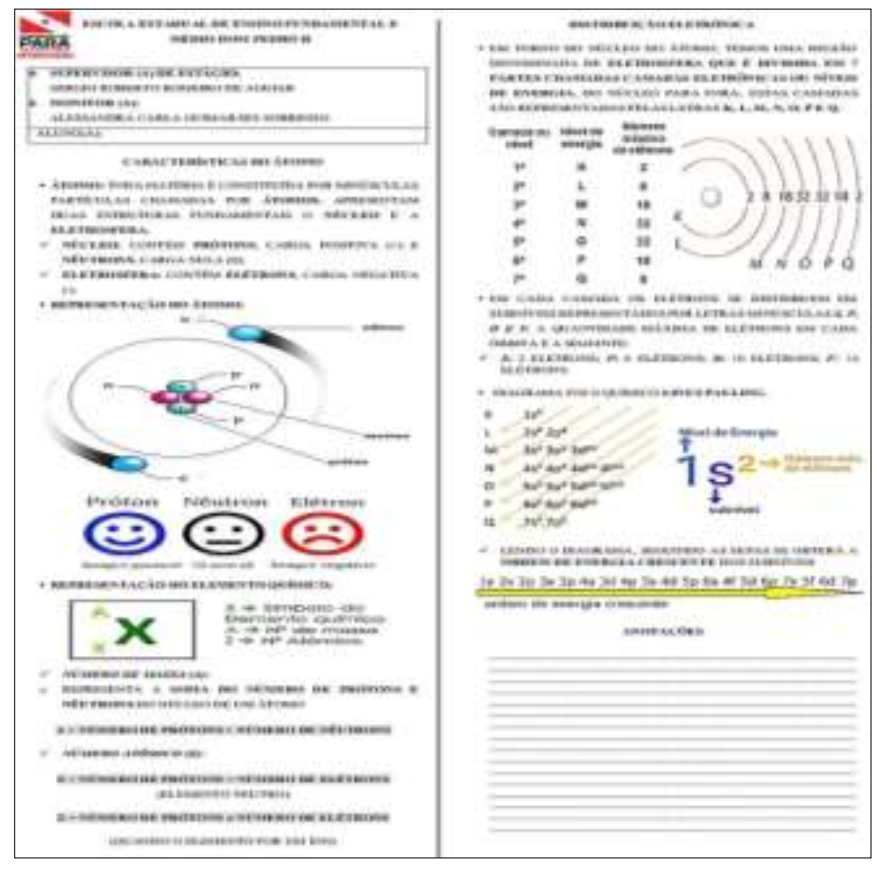

Fonte: Autores.

\subsubsection{Plano de aula C}

- Nome da escola: Escola Estadual de Ensino Fundamental e Médio Dom Pedro II,

- Nome da Estagiária: Alessandra Carla Guimarães Sobrinho

○ Tema da aula: Tabela periódica.

○ Público-alvo: $2^{\circ}$ ano do Ensino Médio

- Carga horária: $90 \mathrm{~min}(2 \mathrm{H} / \mathrm{AULA})$.

○ Procedimentos Metodológicos:

$\checkmark$ A aula foi teórica expositiva, interativa e dialogada, contendo: levantamento dos conhecimentos prévios dos alunos. Inicialmente foi apresentado o tema do dia e o tópico a ser abordados em sala de aula. Foram utilizados os seguintes recursos didáticos: apostila (Figura 5), quadro e pincel. Ao final da aula foi proposto exercícios de fixação para avaliar a aprendizagem dos alunos em relação a temática. 
Figura 5 - Apostila elaborada para a aula de tabela periódica.

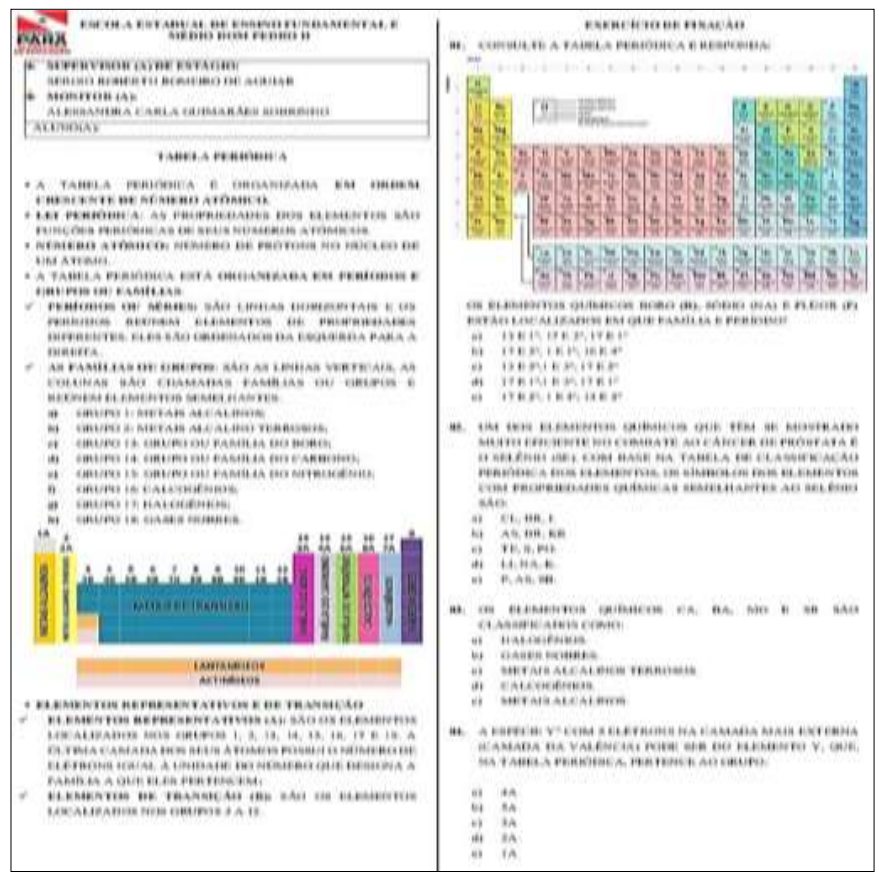

Fonte: Autores.

Foram desenvolvidos os planos de aula com a utilização de ferramentas que pudessem despertar o interesse dos alunos para uma melhor interação e compreensão do assunto apresentado (Lorenzon et al., 2020). Agregando a formação docente princípios pedagógicos importante, como: a ação educativa mais eficiente, em acordo com o cotidiano escolar, essa experiencia possibilitou a interdisciplinaridade e a prática de algumas habilidade e competências, foi possível vivenciar mais de perto alguns dilemas da profissão, fazendo uma reflexão positiva em relação ao ofício docente, consolidando alguns conceitos prévios, além de auxiliar na construção de novos conceitos. De acordo com os autores Souza \& Gonçalves (2012), não basta que o aluno estagiário realize práticas no estágio supervisionado, também é necessário momentos de reflexão dos diagnósticos e das vivências experimentadas durante o período do estágio.

A prática docente me fez entender a necessidade da reflexão-ação-reflexão no ensino, pois o processo educativo é amplo e complexo, mas deve ser adequado a cada realidade escolar, e por mais que as mudanças no sistema sejam difíceis elas são possíveis de se fazer quando lançamos mão de estratégias eficientes na atuação docente. As atividades desenvolvidas durante o estágio, contribuiu para a desconstrução da forma conteudista de "ensinar" e de se "aprender" a teoria, pois utilizar metodologias que fortaleçam o censo critico dos alunos, viabilizam o ensino de forma criativa e motivadora através de um ensino dinâmico, utilizando ferramentas cotidianas para assuntos tão importantes para a sociedade, tal como a poluição da água e a importância da sua preservação, de uma forma descontraída e prazerosa, sendo capaz de dar o suporte necessário para a construção do conhecimento para a formação de cidadãos conscientes.

E para que essa experiência fosse possível foi necessário planejamento. O planejamento de ensino é um ato de movimento, que são percebidos quando se tem a necessidade de ações no ensino. Essas ações devem ser bem elaboradas em todas as etapas do trabalho escolar, assegurando um ensino efetivo que habilite e tenha o compromisso de envolver todos e estimulando as atividades de aprendizagem, em um ambiente que favoreça o desenvolvimento pessoal e que oportunize o trabalho em equipe. 


\subsection{Relato final no estágio supervisionado II}

O Estágio Supervisionado II foi uma oportunidade de vivenciar experiências e de obter diversos aprendizados. O estágio possibilitou uma responsabilidade social para a formação docente, desenvolvendo os alunos para uma formação de alunos inovadores, críticos e autônomos. O compromisso em contribuir no processo de ensino-aprendizagem, deve ser contínuo, sabendo que todos fazem parte dessa construção e mesmo com as dificuldades para a construção dessa identidade docente é necessário correções em relação aos modus operandi vigentes, disciplina e planejamento, para que seja possível transpor as dificuldades. Estar em sala de aula oportunizou grandes aprendizagens, pude observar as diferentes realidades, pois a escola se mostrou um espaço vivo e de discussões tanto de professores quanto de alunos.

Assisti alguns filmes durante o desenvolvimento do estágio, sugestões propostas pelo curso para que eu pudesse compreender algumas situações que ocorrem e que poderiam estar presentes no ambiente escolar e pude extrair conhecimentos valiosos que foram possíveis de serem aplicados em sala de aula. Durante o estágio não vivenciai nenhuma confusão de estudantes bagunceiros e desrespeitosos como no Filme "O Mestre com carinho", mas pude entender que é melhor escolher revelar a afetividade em meio à situações como essas, transformando os alunos por meio de ações sensíveis, tendo pulso firme e fazendo o uso de métodos que contornem as dificuldades na educação e que auxiliem os alunos em sua formação educacional (Filme "Meu mestre, minha vida"), estimulando o pensamento crítico e autônomo dos alunos, que os proporcione ver o mundo de um o ponto de vista diferente do tradicional (Filme Sociedade dos poetas mortos).

Além de ter a percepção enquanto educador-mediador de que cada aluno é diferente do outro e com potencialidades e isso faz toda a diferença (Filme "Adorável professor"). Entendi que a docência precisa fazer a diferença na vida dos alunos como no Filme "Como estrelas na Terra toda criança é especial", sendo uma verdadeira educação (Filme "O Primeiro aluno da classe), construindo um ensino resiliente, para que os alunos não desistam do conhecimento (Filme "O menino que descobriu o vento"), com compromisso e reflexão continua sobre o que podemos alcançar com a educação quando temos vontade e desejo de transformar a realidade (Filme "Uma lição de vida").

Durante a nossa curta estadia no mundo passamos por momentos em que devemos escolher caminhos, e quando falamos em educação isso não é diferente, pois permitir o desenvolvimento dos diferentes atores educacionais é o caminho fundamental para o desenvolvimento educacional. A escola tem um papel essencial, que de acordo com White (2007), nela a criança participa de um processo de aprendizagem ensinando como participar da vida social fora do contexto familiar. Além de poder despertar e desenvolver o poder de iniciativa e o espírito de cooperação social, através da interação com as famílias dos alunos, estimulando e favorecendo as iniciativas em favor da educação, mantendo uma relação constante e fazendo proveito dessa cooperação, envolvendo os pais, os professores, a imprensa e todas as demais instituições diretamente interessadas na obra solidária da educação, ampliando suas fronteiras para o maior número possível de direções, recorrendo a comunidade como à fonte que lhes há de proporcionar todos os elementos necessários para influir, transformando-se num centro poderoso de criação, atração e irradiação de todas as forças e atividades educativas.

Toda essa explanação é para afirmar e reafirmar a importância do estágio na formação docente, pois é o primeiro contato para a construção da identidade profissional, que será modelada através das relações externas e é influenciado por múltiplos contextos, os autores Scalabrin \& Molinari (2013, p. 05) afirmam: “[...] o estágio supervisionado deve acontecer durante a vida acadêmica começando com a observação, com atividades complementares, práticas pedagógicas e isso acabarão proporcionando mais probabilidade de sucesso no estágio e na sua formação profissional”.

A identidade docente é uma construção que se modifica ao longo da vida, sendo influenciada de acordo com as experiências vivenciadas dentro da sociedade, essa construção é cotidiana, e deve levar em consideração a heterogeneidade no processo educacional, mas com a diretriz o tratamento igualitário. O processo de ensino-aprendizagem, deve compreender o 
professor como mediador do processo para que os alunos possam ser agentes modificadores da sua realidade, e assim despertar o interesse dos alunos, sem competições ou autoritarismo e sem preconceitos, auxiliando na formação cidadã.

Precisamos encontrar orientações claras quanto à finalidade da educação, para que possamos proporcionar a todos, sem exceção, uma educação que auxilie na construção de uma sociedade justa, permitindo o pleno desenvolvimento de todos os indivíduos, que segundo Dewey, (2002): “Aquilo que o pai mais diligente e sensato deseja para o seu próprio filho, a comunidade deverá desejá-lo para todas as crianças que crescem no seu seio. Qualquer outro ideal para as nossas escolas é limitado e pernicioso; posto em prática, destruirá a nossa democracia. Tudo o que a sociedade alcançou para seu benefício é posto, por intermédio da escola, ao dispor dos seus futuros membros, bem como todas as suas utopias, que ela espera realizar através das novas possibilidades assim abertas ao seu futuro corpo. Aqui, o individualismo e o socialismo estão em harmonia. Só permitindo o pleno desenvolvimento de todos os indivíduos que a compõem poderá a sociedade eventualmente manter-se fiel à sua razão de ser".

Devemos ter esperança na educação do verbo esperançar de Paulo Freire (1992):“É preciso ter esperança, mas ter esperança do verbo esperançar; porque tem gente que tem esperança do verbo esperar. E esperança do verbo esperar não é esperança, é espera. Esperançar é se levantar, esperançar é ir atrás, esperançar é construir, esperançar é não desistir! Esperançar é levar adiante, esperançar é juntar-se com outros para fazer de outro modo...”

A educação pode ser um sonho possível, quando se tem amor e esperança na profissão docente. $\mathrm{O}$ amor não se separa da esperança, eles norteiam o trabalho do professor (Freire, 1982, p. 99-100): Ai de nós, educadores, se deixarmos de sonhar sonhos possíveis. E o que é que eu quero dizer com sonhar o sonho possível? [...] O sonho viável exige de mim pensar diariamente a minha prática: exige de mim a descoberta [...] sonho possível tem que ver exatamente com a educação libertadora, não com a educação domesticadora [...] educação libertadora enquanto prática utópica. Mas não utópica no sentido do irrealizável; não utópica no sentido de quem discursa sobre o impossível [...]. Utópica no sentido de que esta é uma prática que vive a unidade dialética, dinâmica, entre a denúncia e o anúncio[...] (Freire, 1982, p.99-100).

Estar preparado como educador é estar apto a enfrentar os desafios impostos por uma sociedade dinâmica e diversa. Ser educador significa estar em constante compromisso com a construção de uma nova realidade (Zych \& Ujiie, 2008). "Se a educação sozinha não transforma a sociedade, sem ela tampouco a sociedade muda. Se a nossa opção é progressista, se estamos a favor da vida e não da morte, da equidade e não da injustiça, do direito e não do arbítrio, da convivência com o diferente e não de sua negação, não temos outro caminho se não viver plenamente a nossa opção. Encará-la, diminuindo assim a distância entre o que dizemos e o que fazemos" (Freire, 2000, p. 67).

\section{Considerações Finais}

O estágio proporcionou-me uma mudança de visão com relação a instituição de ensino, me ensinou a aprender de forma significativa para um desenvolvimento de habilidades e competências nas questões da docência, como o respeito aos alunos, familiares e colaboradores. O estágio me permitiu vivenciar a responsabilidade social que a educação tem, contribuindo para a formação de alunos inovadores, críticos e autônomos, além de desenvolver meu potencial, me esperançando nessa futura profissão.

Aprendi e pude ensinar, utilizando como abordagens reflexivas e significativa dos conteúdos para o melhor desenvolvimento cognitivo dos alunos. Com relação ao envolvimento no estágio em docência e ao desenvolvimento das atividades, tive o compromisso de contribuir no processo de ensino-aprendizagem, de modo a favorecer um espaço de desenvolvimento colaborativo e também autônomo, fazendo mediações inclusivas dos alunos sabendo que eles devem ser agentes ativos e participativos do processo de aprendizagem, estimulei a criatividade e o pensamento crítico, sempre 
lembrando que meu papel é de desenvolver cidadãos atuantes em seus contextos sociais, procurando estabelecer relações entre os conhecimentos apresentados com os assuntos importantes da vida.

De acordo com Paulo Freire (2002), a educação é um ato libertador dos cidadãos, emancipa e instiga o homem à humanização de si, uma libertação que transforma, sendo um processo contínuo de reflexão e ação. A libertação, por isto, é um parto. E um parto doloroso. O homem que nasce deste parto é um homem novo que só é viável na e pela superação da contradição opressores-oprimidos, que é a libertação de todos. A superação da contradição é o parto que traz ao mundo este homem novo não mais opressor, não mais oprimido, mas homem libertando-se. (Freire, 1987, p. 35).

A educação libertadora não se trata de educar para o mercado de trabalho apenas, mas a educação é um ato de resistência para a transformação de vidas, quando não entendemos o poder que a educação tem para a sociedade, condenamos as gerações que estão e as futuras, porém se a educação cumpre seu papel original, que é o de formar cidadãos, teremos uma sociedade justa, com acesso a formação de qualidade para todos. Com a educação cidadã e libertadora teremos uma sociedade transformada, veremos os "diplomas" atuando na sociedade, eles saíram felizes de suas molduras, transformaram a si mesmos e ganharam o mundo ao transformar a sociedade onde vivem, estes serão presenteados com riquezas inestimáveis, como o "ouro" da equidade social, o "incenso" da honestidade e a "mirra" da educação, pois ela cura a sociedade.

Por fim, acreditamos na importância dessa temática, pois mesmo em cursos não presenciais, o estágio supervisionado continua sendo importante para as observações e vivencias no exercício da profissão docente, capacitando e auxiliando na construção da identidade docente de forma adequada. Nesse sentido, o estudo apresentado poderá servir de base e modelo descritivo, sendo útil para trabalhos futuros relacionados a educação na região Amazônica, sendo reprodutivo, favorecendo o desenvolvimento da sociedade.

\section{Agradecimentos}

A Universidade de Uberaba (UNIUBE-EaD), pela oportunidade de realização do curso de Licenciatura em Química e toda a equipe da Escola Estadual de Ensino Fundamental e Médio Dom Pedro II, pelo ambiente educacional oferecido para que fosse possível esse relato.

\section{Referências}

Brasil (1996). Lei de Diretrizes e Bases da Educação Nacional, LDB. 9394/1996.

Brasil (2008). Ministério da Educação. Secretaria de Educação Básica. Base Nacional Comum Curricular. Brasília-DF.

Brasil (2008). Lei $n^{o} 11.788$, de 25 de setembro de 2008. Dispõe sobre o estágio de estudantes e dá outras providências. Diário Oficial da União, Brasília.

Carmo, J. dos S. (2012). Fundamentos psicológicos da educação. Curitiba: InterSaberes,

Cedac - Comunidade educativa (2013). O que revela o espaço escolar: um livro para diretores de escola. São Paulo: Editora Moderna.

Cruz, Y. W. L. B. (2017). A disciplina de Bioquímica na formação de profissionais da saúde: percepção de alunos do Curso de Enfermagem da Faculdades São José. Ciência Atual, 9(1):2-11.

Dewey, J. (2002). A escola e a sociedade e a criança e o currículo. Lisboa: Relógio d’Água Editores.

Eskenazi, E. S; Martins, M. A. \& Ferreira J. M. (2013). Tele- educação e monitoria ativa no ensino da saúde bucal a estudantes de medicina. Revista Brasileira de Educação,

Frago, A. V. \& Escolano, A. (1998). Currículo, espaço e subjetividade: a arquitetura como programa. Tradução: Alfredo Veiga-Neto. Rio de Janeiro: DP\&A.

Freire, P. (1982). Educação: o sonho possível. In: Brandão, C. R. (Org.). O educador: vida e morte - escritos sobre uma espécie em perigo. Rio de Janeiro: Graal.

Freire, P. (1987). Pedagogia do Oprimido. Rio de Janeiro: Paz e Terra.

Freire, P. (1992). Pedagogia da Esperança: um reencontro com a Pedagogia do Oprimido. Rio de Janeiro: Paz e Terra. 
Freire, P. (2000). Pedagogia da Indignação, cartas pedagógicas e outros escritos. São Paulo: Editora Unesp, p.31-32.

Freire, P. (2002). Pedagogia da Autonomia. Rio de Janeiro: Paz e Terra.

Frison, L. M. B. (2016). Monitoria: uma modalidade de ensino que potencializa a aprendizagem colaborativa e autorregulada. Pro-Posições, $27(1): 133-153$.

Garcia, L. T. S. \& Queiroz, M. A. (2009). Embates pedagógicos e organizacionais nas políticas de educação. Natal: Ed. da UFRN.

Garcia, P. (2017). A localização e o entorno da escola: limitação ou ampliação das oportunidades educacionais? Educativa. 19.

Google Earth (2022). Google Earth website. http://earth.google.com/.

Guedes, J.; Silva, A. \& Garcia, L. (2017). Political-pedagogical project in the perspective of a human rights education: a theoretical essay. Revista Brasileira de Estudos Pedagógicos. n. 98, p. 580-595.

Haag, G. S, Kolling, V.; Silva, E. \& Melo, S. C. B. (2008). Contribuições da monitoria no processo ensino- aprendizagem em enfermagem. Revista Brasileira de Enfermagem, 61(2):215-220.

Lorenson, G. A.; Pereira, G. A.; Mariano, N. M. (2020). O uso do jogo no processo de ensino e aprendizagem da tabela periódica: avaliação de uma intervenção do estágio de regência em química. Research, Society and Development, [S. 1.], v. 9, n. 8, p. e47985324.

Mota, P. A. T..; Barbosa, T.; Dublante, C. A. S.; Ribeiro, D. Dos R..; Silveira, F. M. Da.; Almada, F. De A. De C.; Silva, I. M. De O. (2021). O desafio da formação docente. Research, Society and Development, [S. 1.], v. 10, n. 12, p. e193101220238.

Nascimento, F. B. \& Barletta, J. B. (2011). O olhar do docente sobre a monitoria como instrumento de preparação para a função de professor. Revista CEREUS, 3(1):75- 87.

Pereira, I. M. S. (2018). Relato de experiências do estágio supervisionado na universidade e no campo. Revista Educação em Foco, n. 10.

Pimenta, S. G. \& Lima, M. S. L. (2012). Estágio e docência. São Paulo: Cortez.

PPP - Projeto Político Pedagógico (2021). Escola Estadual Ensino Fundamental e Médio Dom Pedro II.

Reis, M. F.; Machado, A. M.; Martin, R. A. \& Inada P. (2008). Acadêmicos de Ciências Biológicas: investigações sobre formação docente. Revista Saúde e Pesquisa, 1(2):103-109.

Roesch, S. M. A. (1996). Projetos de estágio do curso de administração: guia para pesquisas, projetos, estágios e trabalho de conclusão de curso. 2. ed. São Paulo: Atlas.

Scalabrin, I. C. \& Molinari, A. M. C. (2013). A importância da prática do estágio supervisionado nas licenciaturas. UNAR, v. 17, n. 1.

Silva, M. G. (2016). Marco da Légua: a topografia da (in)diferença e as metamorfoses urbanísticas em um bairro interclassista em Belém. Tese apresentada à Banca Examinadora da Pontifícia Universidade Católica de São Paulo, como exigência parcial para obtenção do título de Doutora em Ciências Sociais. PUC: São Paulo.

Soares, J. F. (2004). O efeito da escola no desempenho cognitivo de seus alunos. Revista Electrónica Iberoamericana sobre Calidad, Eficacia y Cambio en Educación (REICE), v. 2, n. 2.

Sousa, K. H. J. F. \& Fernandes, M. A. (2016). Vivência acadêmica com a docência no programa de monitoria em saúde mental. Revista Interdisciplinar, 9(3):149-152.

Souza, F. M. S. \& Gomide, L. B. (2013). Experiência de monitoria no ensino de psicologia da Aprendizagem. Realização-Revista on-line de Extensão e Cultura, 1(1):67-78.

Souza, M. D. A. \& Gonçalves, A. E. C. (2012). Relato de Experiências vivenciadas durante o Estágio Supervisionado no ensino de Ciências em uma Escola de educação básica em Itapipoca-CE. Anais IV FIPED... Campina Grande: Realize Editora.

Uniube (2021). Letras - Inglês @ Para Portadores De Diploma De Licenciatura Em Letras - EAD/Uniube.

White, E. G. (2007). Conselhos aos professores, pais e estudantes. 5. ed. Tatuí: Casa Publicadora Brasileira, 2007.

Zych, A. C. \& Ujiie, N. T. (2008). O instigador Paulo Freire e os entornos da diversidade. Travessias. 